\title{
Terminal Telomere Repeats Are Actually Short in Telomerase-Negative Immortal Human Cells
}

\author{
Tohru Higaki, ${ }^{a}$ Taro Watanabe, ${ }^{a}$ Ichiro Tamatomi,${ }^{a}$ Hidetoshi Tahara, ${ }^{a}$ Masanobu Sugimoto, ${ }^{b}$ \\ Yasuhiro FURUICHI, ${ }^{b}$ and Toshinori IDE ${ }^{*, a}$ \\ ${ }^{a}$ Department of Cellular and Molecular Biology, Graduate School of Biomedical Sciences, Hiroshima University; 1-2-3 \\ Kasumi, Minami-ku, Hiroshima, Hiroshima 734-8551, Japan: and ${ }^{b}$ GeneCare Research Institute; 200 Kajiwara, \\ Kamakura, Kanagawa 247-0063, Japan. \\ Received August 13, 2004; accepted September 10, 2004; published online September 16, 2004
}

\begin{abstract}
Telomerase-negative immortal human cells maintained telomere length by a mechanism called alternative lengthening of telomeres (ALT mechanism). These cells (ALT cells) have two prominent characteristics of long telomere repeats at each chromosome end revealed by Southern blotting (terminal restriction fragments: TRF) and the presence extrachromosomal telomere repeat (ECTR) DNA. We report here that the TRF length of ALT cells revealed by the conventional unidirectional (UD) current or pulse-field (PF) current electrophoresis appeared to be over estimated. The TRF length determined by the pulse inverse-field (PIF) current electrophoresis (2-9 kbp depending upon cell lines) was much smaller than that (ca. $23 \mathrm{kbp}$ ) by UD or PF current electrophoresis. These results were in consistent with very weak telomere staining in situ at chromosome ends in ALT cells. When a mixture of HinfI-digested genomic DNA of human diploid fibroblasts and synthetic telomere repeat DNA with similar size of ECTR DNA was electrophoresed using a UD current, the apparent TRF size shifted to larger molecular weight, while the size shift did not occur by PIF current electrophoresis. These results together with other data indicate that the unusually long TRF of ALT cells determined by using conventional electrophoresis is an artifact produced by a complex formed by short TRF and short ECTR DNA.
\end{abstract}

Key words telomerase-negative immortal cell; terminal restriction fragment; telomere repeat

Telomeres of eukaryotic cells are DNA-protein complexes that cap chromosome ends and protect them from degradation and end-to-end fusion. Human telomere DNA consists of a tandemly repeated G-rich sequence unit, 5'-(TTAGGG)$3^{\prime}$ towards the end of the chromosome. ${ }^{1)}$ Normal human somatic cells in culture divide only a finite number of times and finally stop proliferation, because telomere DNA shortens at each replication due to incomplete replication at the extreme $5^{\prime}$ end of the daughter strand and to partial degradation of the template strand from the $5^{\prime}$ end. $^{2-4)}$ Telomere shortening at each division in somatic cells is thought to act as a mitotic clock, signaling the cells to stop proliferation when a certain length of telomere DNA is achieved. ${ }^{5,6)}$ Telomere shortening should be overcome for cells to acquire an unlimited proliferative life span (immortalized), which is generally performed by expression of telomerase activity. ${ }^{7)}$ Most immortal human cells, such as cancer cells and germ tissue cells, have strong telomerase activity. ${ }^{7,8)}$ However, several immortal human cell lines lacking telomerase activity maintain their telomeres telomerase-independently termed "an alternative lengthening of telomeres" (ALT $)^{9,10)}$ by which telomeres are elongated using a recombinational mechanism. ${ }^{11,12)}$ These telomerasenegative immortal human cells, referred to as ALT cells, in culture are believed to retain very long ( $c a .23 \mathrm{kbp}$ or more) and heterogeneous terminal restriction fragments (TRF) of telomere repeats detected by Southern blotting compared with telomerase-negative normal mortal somatic cells and telomerase-positive immortal human cell lines (generally smaller than $10 \mathrm{kbp}$ ). This is observed by Southern blotting not only following to the conventional (unidirectional field) gel electrophoresis but also to the pulse-field gel electrophoresis that is used for analysis of large DNA. ${ }^{9)}$ Retention of long TRFs (ca. $23 \mathrm{kbp})$ is also found in in vivo tumor tissues that lack telomerase activity. ${ }^{13)}$ Unusually long TRFs in these cells are assumed to participate in the mechanisms, such as the recombinational process reported in yeast, ${ }^{14)}$ to maintain telomeres independent of telomerase. The other characteristic of telomerase-negative immortal cell lines is the presence of extrachromosomal telomere repeat (ECTR) DNA that is linear duplex detected by both in situ telomere DNA staining and Southern blotting. ${ }^{15,16)}$ By in situ detection, ${ }^{16)}$ ECTR DNA is detected as extrachromosomal dots with various signal intensities in mitotic cell preparations and is co-localized with the human telomere repeat binding protein-1 (TRF-1). By Southern blotting, ECTR DNA is detected as smear band with small size $(2-4 \mathrm{kbp})$ in genome DNA samples, regardless of digestion with restriction enzymes, from various ALT cell lines but not from telomerasenegative normal and telomerase-positive immortal cells. ECTR DNA possibly acts as a primer or a template for telomere elongation by DNA polymerase in telomerase-negative cells. Yeager et al. $^{17)}$ reported that telomerase-negative immortal cells contain a novel promyelocytic leukemia body named APB that contains promyelocytic leukemia proteins, telomeric DNA, TRF-1 and 2, replication factor A, RAD51, and RAD52. There is an apparent discrepancy between TRF size estimated by Southern blotting and telomere signals observed by in situ staining in ALT cells, i.e., ALT cells has extremely long TRF length by Southern blotting but very weak telomere signals at each chromosome end by in situ detection. This discrepancy is not observed in telomerase-negative normal cells and in telomerase-positive tumor cells or immortal cells. In this paper, we report that TRFs at chromosome ends in ALT cells consist of relatively short telomere repeats, but they appear to be extremely long by Southern blotting, probably because short TRF DNA and a large num- 
ber of ECTR DNA molecules form a large complex artificially during DNA preparation or electrophoresis.

\section{MATERIALS AND METHODS}

Cell Lines Telomerase-negative immortal human cell lines KMST-6, ${ }^{18)}$ SUSM-1, ${ }^{19)}$ WI-38VA13 ${ }^{20)}$ and SaOS-2 ${ }^{21)}$ were used. As control cells, human embryonic normal fibroblasts (telomerase-negative; mortal) TIG-322) and an SV40transformed cell line, SVts8 (telomerase-positive; immortal ${ }^{23)}$ derived from TIG-3, were used. TIG-3 shows the maximal population doubling level (PDL) of approximately 80 . B-N1 was used as an example of mouse cell lines which had very long terminal telomere repeats. ${ }^{24)}$ All cell lines were cultured in Dulbecco's modified Eagle's medium with $10 \%$ fetal bovine serum.

Electrophoresis and Southern Blotting The TRF length was detected by Southern blotting of genomic DNA as we described previously. ${ }^{16}$ ) Purified genomic DNA was digested with a restriction enzyme and was run on $0.7 \%$ agarose gel (LO3 TAKARA, TaKaRa BioMedicals, Shiga, Japan) in 0.5x TBE (0.45 м Tris-borate $\mathrm{pH} 8.3,1 \mathrm{~mm}$ EDTA) buffer using uni-directional (UD) current electrophoresis $(0.75 \mathrm{~V} / \mathrm{cm})$ at room temperature for $15-20 \mathrm{~h}$, or on $1 \%$ agarose (Pulse Field Certified agarose, BioRad, CA.) using pulse inverse-field (PIF) current electrophoresis $(5.3 \mathrm{~V} / \mathrm{cm}$ forward, $3.3 \mathrm{~V} / \mathrm{cm}$ reverse) at $4{ }^{\circ} \mathrm{C}$ for $20 \mathrm{~h}$ or using pulse field (PF) current (angle $\left.120^{\circ}\right)$ electrophoresis $(6 \mathrm{~V} / \mathrm{cm}$, initial switch time $1.0 \mathrm{~s}$, final switch time $13.0 \mathrm{~s}$ ) at $14{ }^{\circ} \mathrm{C}$ for $8 \mathrm{~h}$. Cells $\left(5 \times 10^{5}\right.$ or $1 \times 10^{6}$ cells $\left./ \mathrm{plug}\right)$ embedded in a $0.7 \%$ agarose plug (NuSieve Agarose, FMC BioProducts, ME, U.S.A.) were lysed in an alkaline solution $(50 \mathrm{~mm} \mathrm{NaOH}$, $1 \mathrm{~mm}$ EDTA) and were electrophoresed in the same alkaline solution using a UD current or a PIF current. Southern blotting was done using ${ }^{32} \mathrm{P}$-labeled (TTAGGG) $)_{4}$ as a probe. Restriction enzymes recognized as four bases used for TRF analysis were (recognition sequences are indicated in parentheses): Tsp509I (AATT), Bst UI (CGCG), BfaI (CTAG), $T a q^{\alpha}$ I (TCGA), MseI (TTAA), MnlI (CCTC) purchased from New England Biolabs; AluI (AGCT), RsaI (GTAC), MspI (CCGG) from Nippon Gene; Sau3AI (GATC), HaeIII (GGCC), HhaI (GCGC) from TaKaRa BioMedicals; Hsp92II (CATG) from Promega, and Hinfl (GANTC) from Boehringer Mannheim.

S1 Nuclease Digestion For S1 nuclease digestion, $3 \mu \mathrm{g}$ of Hinfl -digested genomic DNA in $100 \mu \mathrm{l}$ of $30 \mathrm{~mm}$ sodium acetate buffer ( $\mathrm{pH} 4.6$ ) containing $280 \mathrm{~mm} \mathrm{NaCl}$ and $1 \mathrm{~mm}$ $\mathrm{ZnSO}_{4}$ was digested with 10 units of S1 nuclease (TaKaRa BioMedicals) at room temperature for various periods of time.

PCR Amplification of Telomere Repeats and Complex Formation Synthetic oligodeoxynucleotides, (5'-GGT TAG- $\left.3^{\prime}\right)_{20}$ and its opposite strand, were purchased from Sawaday Technology (Tokyo, Japan). Longer telomere repeats of $c a .2 \mathrm{kbp}$ were synthesized using PCR with a synthetic 120-mer, and then $c a .4 \mathrm{kbp}$ were synthesized using a purified $c a$. $2 \mathrm{kbp}$-mer. The standard reaction mixture $(50 \mu \mathrm{l})$ contained $5 \mathrm{pmol}$ primer/template, $5 \mu \mathrm{l} 10 \mathrm{xPfu}$ buffer (Stratagene, LaJolla), $4 \mu 12.5 \mathrm{~mm}$ dNTP, $2.5 \mu 180 \%$ glycerol, $0.5 \mu \mathrm{l}$ Pfu polymerase (2.5 units $/ \mu \mathrm{l})$. The $10 \mathrm{xPfu}$ buffer contained: $200 \mathrm{~mm}$ Tris- $\mathrm{HCl}$ (pH 8.0), $20 \mathrm{~mm} \mathrm{MgCl}_{2}, 100 \mathrm{~mm}$
$\mathrm{KCl}, 60 \mathrm{~mm}\left(\mathrm{NH}_{4}\right) \mathrm{SO}_{4}, 1 \%$ Triton $\mathrm{X}-100$ and $0.1 \%$ nucleasefree bovine serum albumin. The Thermal cycle conditions were: (1) initial denaturation at $94^{\circ} \mathrm{C}$ for $1 \mathrm{~min}$; (2) 40 cycles of denaturation at $94^{\circ} \mathrm{C}$ for $30 \mathrm{~s}$, annealing at $60^{\circ} \mathrm{C}$ for $30 \mathrm{~s}$, and extension at $72^{\circ} \mathrm{C}$ for $90 \mathrm{~s}$. The resulting DNA was purified by phenol-chloroform extraction and was precipitated using ethanol. PCR-amplified telomere repeat DNA $(3 \mathrm{ng} / 30 \mu \mathrm{l})$ was heat denatured at $100^{\circ} \mathrm{C}$ for $5 \mathrm{~min}$ and was rapidly chilled on ice water. Denatured DNA solution was mixed with ethanol-precipitated Hinfl-digested genomic DNA $(3 \mu \mathrm{g})$ from TIG-3 or with ethanol-precipitated pAcHLT-A ( $8.1 \mathrm{kbp})$ plasmid DNA $(3 \mu \mathrm{g})$ which was linearized by EcoRI digestion, and stood for $24 \mathrm{~h}$ at room temperature. The mixture was analyzed by neutral gel electrophoresis using a UD current.

\section{RESULTS}

Telomerase-Negative Immortal Human Cells Have an Apparently Long TRF The TRF length detected by Southern blotting of Hinfl-digested genomic DNA from telomerase-negative immortal human cells is exceptionally long at $23 \mathrm{kbp}$ or over, ${ }^{9,10)}$ which is very different from that of many types of human cultured cells and human tissues (less than $10 \mathrm{kbp}$ ). However, as we reported previously ${ }^{16)}$ in situ detection of telomere repeats using fluorescence in situ hybridization (FISH) or cycling oligonucleotide-primed in situ synthesis (PRINS) shows that telomere signals at each chromosome end of telomerase-negative immortal cells are undetected in KMST- 6 and are weakly detected in SUSM-1 and WI-38VA13, but those of other human cells with a TRF length of around $6-8 \mathrm{kbp}$ are clearly detected. This apparent discrepancy between TRF size estimated by Southern blotting and telomere signals observed by in situ staining in ALT cells could be explained by that the TRF of these cells possibly consisting of short telomeric repeats and long subtelomic (non-telomere repeat) sequences. If so, some restriction enzymes might cut DNA at a subtelomic site closer to the terminal telomere repeats, resulting in a shorter TRF length. To investigate this possibility, genomic DNA of WI-38VA13 was digested with one of 14 4-base recognition restriction enzymes and electrophoresed using uni-directional (UD) current. All restriction enzymes, except Bst $\mathrm{UI}$ (CGCG) and HhaI (GCGC), well digested genomic DNA to various sizes (Fig. 1A). The digestion with two enzymes, Bst $\mathrm{UI}$ and HhaI, was relatively poor, but their enzyme activity was verified because they digested plasmid DNA. The poor activity of these enzymes digesting human genomic DNA is due to the methylation of cytidine in the $\mathrm{CpG}$ sequence. Using Southern hybridization with a probe of telomere repeats, the TRF length of genomic DNA digested by these restriction enzymes was determined as around $23 \mathrm{kbp}$, except that the DNA of TRFs digested by MnlI showed smear signals, as shown in WI-38VA13 (Fig. 1B). Essentially the same results were obtained from the DNA of KMST-6, SUSM-1 and SaOS-2 (data not shown) and the results of Hinfl digested DNA from these cell lines were presented in Fig. 2A. Considering that telomerase-negative immortal cells have weak telomere signals at each chromosome end detected by $\mathrm{FISH}^{16)}$ and that they have apparently very long TRFs shown by Southern blot analysis, a tentative conclusion from these 
A

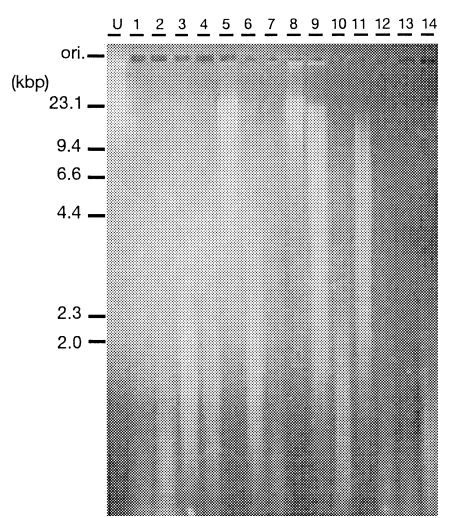

B

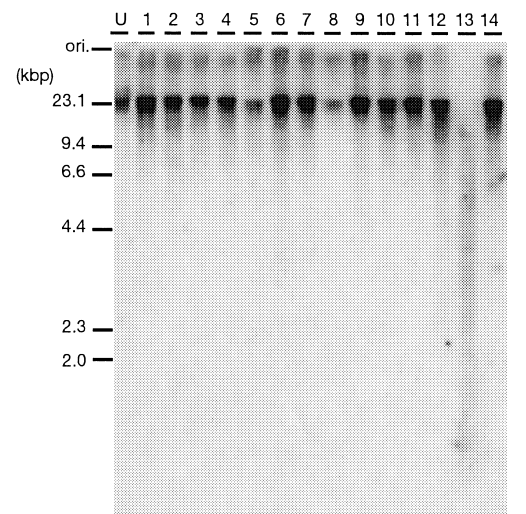

Fig. 1. Apparent TRF Length of Telomerase-Negative Immortal Cells by Using UD Current Electrophoresis

Genomic DNA from WI-38VA13 was digested with various restriction enzymes and was run on $0.7 \%$ neutral agarose gel using a UD current electrophoresis. U, undigested; 1 , Tsp509I; 2, AluI; 3, Sau3AI; 4, HaeIII; 5, HhaI; 6, RsaI; 7, Hsp92II; 8, BstUI; 9, MspI; 10, BfaI; 11, Taq ${ }^{\alpha} \mathrm{I} ; 12, M s e \mathrm{I}$; 13, MnlI; 14, HinfI. After the run, the gel was stained by ethidium bromide (A) and was processed for Southern blotting using telomere probe (B).
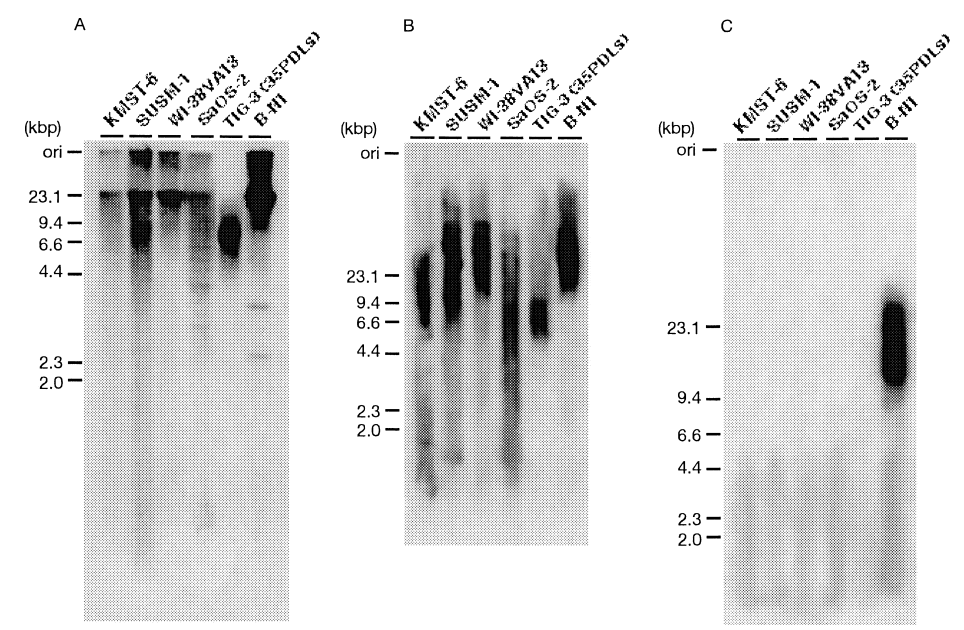

Fig. 2. TRF Length of Telomerase-Negative Immortal Cells by Different Methods of Electrophoresis

DNA was digested with Hinfl and run on $0.7 \%$ neutral agarose gel using a UD current (A), on $1 \%$ neutral agarose gel using a PF current electrophoresis (B), or on $1 \%$ neutral agarose gel using a PIF current electrophoresis (C).

results is that these telomerase-negative immortal cells have an extremely long subtelomic region with rare recognition sites for restriction enzymes, except for MnlI sites (CCTC).

$\mathrm{PF}$ current electrophoresis is used for analysis of very large DNA such as whole chromosomal DNA from yeast. TRF length of mouse cells (B-N1) is known to be very long (over $23 \mathrm{kbp}$ ) not only by Southern blotting but also by quantification of telomere repeats by chromosome staining, ${ }^{24)}$ and it was confirmed to be always long by 3 different methods of electrophoresis (Fig. 2). The telomeres in ALT cells are very heterogeneous in length, ranging from very long to very short by PF current electrophoresis. $\left.{ }^{9}{ }^{25}\right)$ TRF of Hinfl-digested genomic DNA from ALT cells gave compressed discrete band at around $23 \mathrm{kbp}$ by conventional UD current electrophoresis as shown in Figs. 1B and 2A, but the same DNA gave decompressed smear band with various sizes depending upon cell lines (Fig. 2B). Hinfl-digested genomic DNA from normal fibroblasts, TIG-3, gave smear TRF band (around $6-9 \mathrm{kbp}$ ) by both UD and PF current electrophoresis.

TRF Length Was Short When Analyzed by Southern Blot Using Pulse Inverse-Field Neutral Gel Electrophoresis Surprisingly, when restriction enzyme-digested genomic
DNA from ALT cells were analyzed by PIF current electrophoresis, a dramatic reduction of TRF size of telomerasenegative (ALT) cells was observed: a shift from $23 \mathrm{kbp}$ signals by UD current electrophoresis to small smear signals (Fig. 2C). We confirmed more precisely that the size of apparent telomere repeat signal of ALT cells was shifted from about $23 \mathrm{kbp}$ by UD current electrophoresis (Fig. 3A) to around 2-6 kbp (KMST-6 and SaOS-2), 2-9 kbp (SUSM1) or around $9 \mathrm{kbp}$ (WI-38VA13) by PIF current electrophoresis (Fig. 3B). This order of TRF length detected by PIF current electrophoresis was roughly correlated with that of fluorescent intensity of telomere repeats as we reported previously. ${ }^{16)}$ The TRF length of restriction enzyme-digested genomic DNA from the normal fibroblast TIG-3 was about $9 \mathrm{kbp}$ using UD current electrophoresis (Fig. 3A) and was reduced to $6 \mathrm{kbp}$ using a PIF current (Fig. 3B), i.e., a reduction in TRF length by PIF current electrophoresis occurred but was not so dramatic. Dramatic reduction of TRF size by PIF current electrophoresis did not observed either in telomerasepositive immortal fibroblast cell line, SVts 8 (data not shown). A dramatic reduction in TRF length by PIF current electrophoresis was solely observed in DNA from ALT cells containing ECTR DNA. Thus, the TRF DNA from ALT cells 


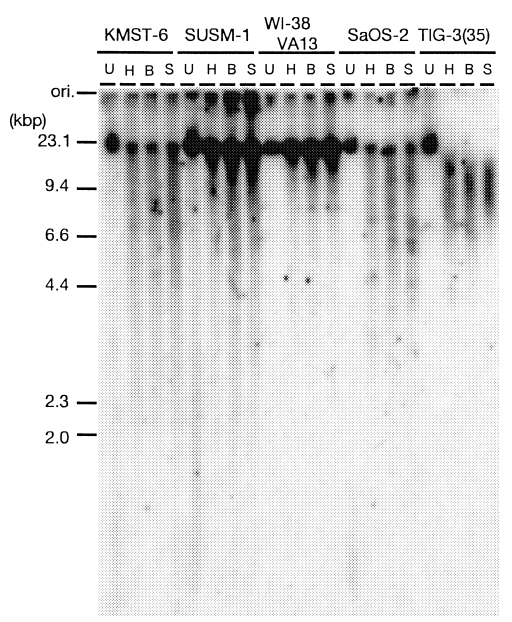

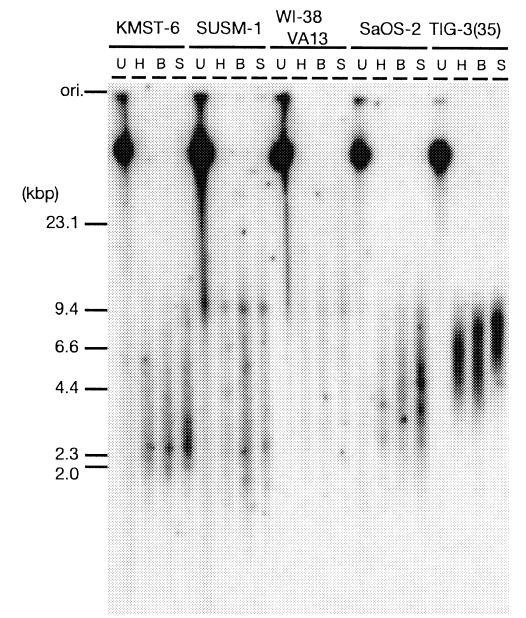

Fig. 3. TRF Length of Telomerase-Negative Immortal Cells

Genomic DNA was digested with restriction enzymes and run on $0.7 \%$ neutral agarose gel using a UD current (A) or on $1 \%$ neutral agarose gel using a PIF current electrophoresis (B). U, undigested; H, Hinfl digested; B, BfaI digested: S, Sau3AI digested. TIG-3 cells were used at 35 PDL.

is in fact not very long, but appears to be long because of a possible association with ECTR DNAs.

Southern Blotting by Alkaline Electrophoresis of Agarose-Embedded Cells From in situ detection of telomere repeats, ALT cells have ECTR DNA as detected extrachromosomal spots with various sizes and have very weak telomere signals at each chromosome end. However, we could not estimate the amount of telomere repeats distributed between the TRF and ECTR fractions. To have an approximate idea, cells embedded in agarose plug were lysed in an alkaline solution and were electrophoresed in the alkaline solution using either a UD current or a PIF current. In this alkaline condition, telomeres at the end of undigested genomic DNA should be retained at the position of cell loading. ECTR signals (smear at around $1-4 \mathrm{kbp}$ ) were detected by Southern blotting exclusively in four telomerase-negative immortal cell lines, but not in telomerase-negative mortal TIG3 cells and telomerase-positive immortal SVts8 cells (Figs. 4A, B). The Alu sequence, used as a marker of genomic DNA, was exclusively detected at the position of embedded cells and was not detected in low-molecular-weight fractions (data not shown). The ECTR signal intensity was stronger using a PIF current than using a UD current electrophoresis, probably because the association of ECTR DNA with genomic DNA was prevented using PIF current electrophoresis. The proportions of the ECTR signal intensity to total telomere signal were $82.8 \%, 82.4 \%, 80.8 \%$, and $74.8 \%$ in KMST6, SaOS-2, SUSM-1, and WI-38VA13, respectively. As part of ECTR DNA might be still trapped in genomic DNA even using PIF current alkaline electrophoresis, the proportion of ECTR sequences estimated here would be an underestimation.

Digestion with S1 Nuclease ALT cells appeared to have a large amount of telomere repeat DNA extrachromosomally whose size is as small as $1-4 \mathrm{kbp}$. If the telomere repeat DNA at chromosome ends of ALT cells has frequent nicks and gaps or alkaline labile lesions, it should migrate faster in the alkaline gel electrophoresis, and we cannot conclude that fast-migrating signals represent ECTR. If $1-4 \mathrm{kbp}$ telomere signals in alkaline agarose gel is derived from telomere re-

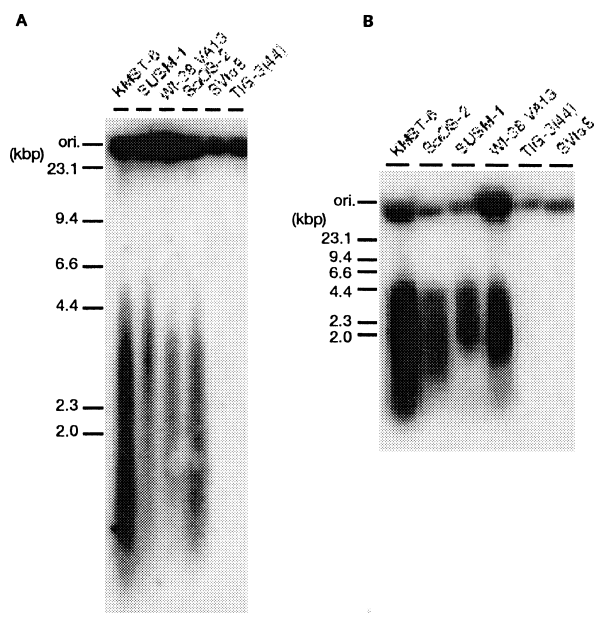

Fig. 4. Detection of Telomere Repeats by Southern Blotting after Alkaline Electrophoresis of Agarose-Embedded Cells

Cells embedded in an agarose plug were lysed in an alkaline condition, and were alkaline-electrophoresed using either a UD current (A) or a PIF current (B). TIG-3 cells were used at $44 \mathrm{PDL}$.

peat DNA with frequent nicks at the chromosome ends, small telomere signals could be observed by neutral gel electrophoresis after digestion of genomic DNA with S1 nuclease. The telomere signal of HinfI-digested or undigested genomic DNA at around or over $23 \mathrm{kbp}$ obviously completely disappeared after S1 nuclease digestion for 5 min giving a very wide smear with neutral electrophoresis using a UD current (Fig. 5A). Digestion with S1 nuclease occurred within $5 \mathrm{~min}$ and the results did not change by further incubation with $\mathrm{S} 1$ nuclease. These results indicated that the TRF around or over $23 \mathrm{kbp}$ contained frequent nicks. While undigested genomic DNA gave a signal indicating a very large molecular weight with neutral electrophoresis using a PIF current, it gave a smear signal at around $1-6 \mathrm{kbp}$ after $\mathrm{S} 1$ nuclease digestion (Fig. 5B). Genomic DNA digested with both HinfI and S1 nuclease showed smear signals with a smaller molecular weight by electrophoresis using a PIF current than that digested with S1 nuclease alone. It should be emphasized that a similar result was obtained from normal 
A

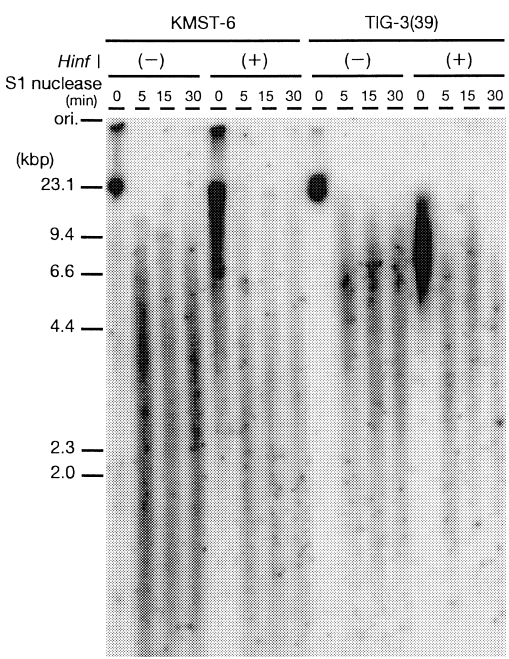

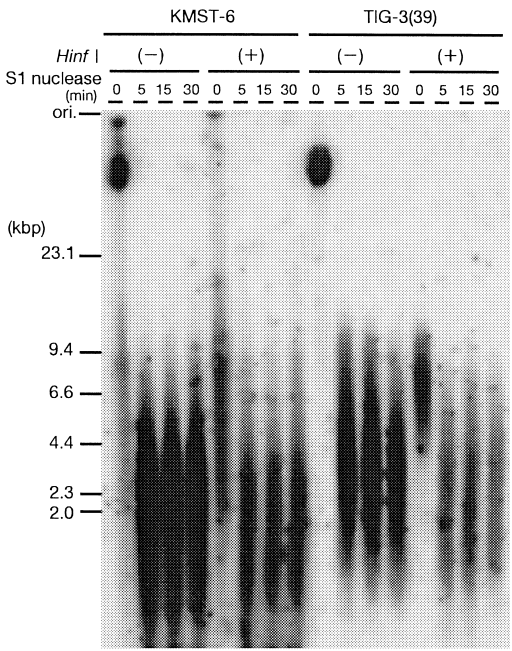

Fig. 5. S1 Nuclease Digestion of Genomic DNA

Genomic DNA from KMST-6 or TIG-3 (39 PDL) cells was digested (+) or undigested ( - ) with Hinfl and was successively digested with S1 nuclease for the indicated periods (min). DNA was run on $0.7 \%$ neutral agarose gel using UD current (A) or on $1 \%$ neutral agarose gel using a PIF current (B) and was Southern blotted.

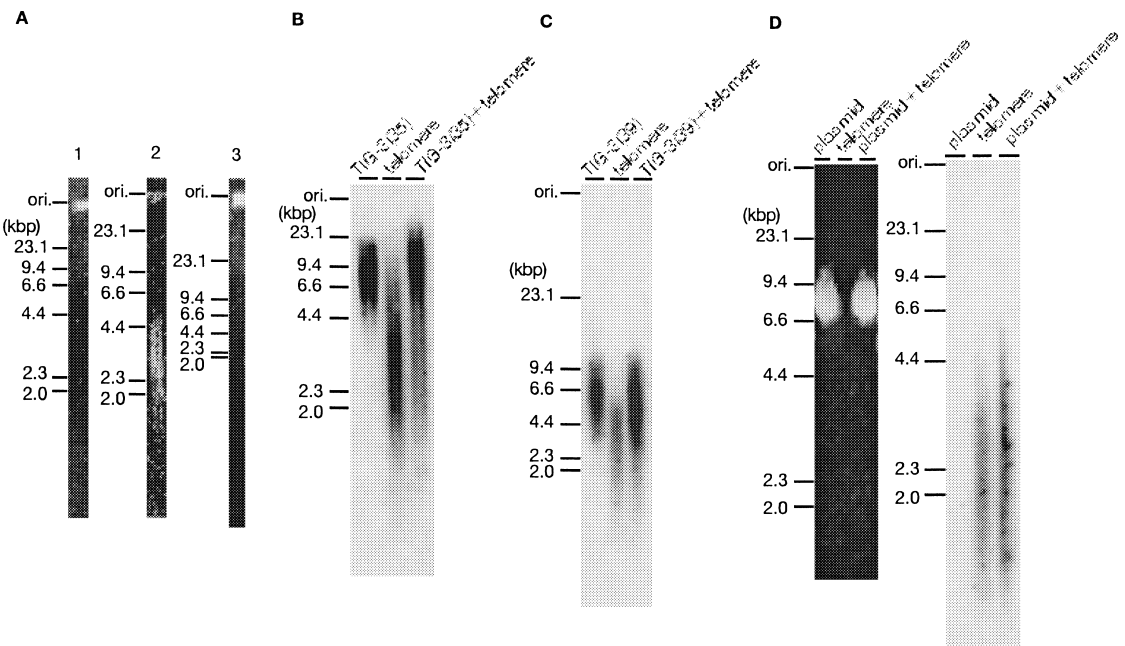

Fig. 6. Mixing of Genomic DNA with Synthetic Telomere Repeat DNA

(A) PCR amplified telomere repeat DNA ( $3 \mu \mathrm{g} / \mathrm{lane}$ ) was run on neutral agarose gel using UD current (1), alkaline agarose gel using a UD current (2), or neutral agarose gel using a PIF current (3) and was stained with ethidium bromide. (B and C) Hinfl-digested genomic DNA ( $3 \mu \mathrm{g})$ from TIG-3 cells, PCR-amplified synthetic telomere repeats ( 3 ng), or a mixture of them was run on $0.7 \%$ neutral agarose gel using a UD current (B) or on $1 \%$ neutral agarose gel using a PIF current (C) and was Southern blotted using telomere probe. (D) A plasmid DNA ( $3 \mu \mathrm{g})$, pAcHLT-A ( $8.1 \mathrm{kbp})$, linearized by EcoRI digestion (lane p), PCR-amplified synthetic telomere repeats (3 ng), or a mixture of them was run on $0.7 \%$ neutral agarose gel using a UD current. The gel was stained with ethidium bromide (left 3 lanes) and then Southern blotted using telomere probe (right 3 lanes).

fibroblast, TIG-3 (Figs. 5A, B). These results clearly indicated that TRF of ALT cells have many nicks and gaps as TIG-3 have, and we conclude that fast-migrating signals (1$4 \mathrm{kbp})$ in the alkaline gel exclusively observed in DNA from ALT cells represent ECTR DNA.

Interaction between Genomic DNA and Synthetic Telomere Repeats To determine the possible interaction and complex formation among telomere repeat DNA fragments, telomere repeat DNA $(2-4 \mathrm{kbp})$ was prepared by PCR amplification. When $3 \mu \mathrm{g} / 30 \mu \mathrm{l} /$ lane of PCR product was run on alkaline agarose gel electrophoresis using a UD current, a smear signal around $2-4 \mathrm{kbp}$ was observed (Fig. 6A lane 2). When the same amount of PCR product was run on neutral agarose gel using either a UD or a PIF current, DNA did not enter into the gel but remained in the sample well probably because of a formation of a large DNA complex or network which could not be resolved by PIF current electrophoresis (Fig. 6A lanes 1, 3). However, 3 ng/30 $\mu \mathrm{l} /$ lane of telomere repeat DNA amplified by PCR gave a $3-4 \mathrm{kbp}$ smear even with neutral gel electrophoresis using a UD current (Fig. 6B), probably because the diluted condition prevented the formation of a complex. PCR-amplified telomere repeat DNA $(3 \mathrm{ng} / 30 \mu \mathrm{l})$ was heat denatured at $100^{\circ} \mathrm{C}$ for 5 min and was rapidly chilled on ice water. Denatured DNA solution was mixed with ethanol-precipitated Hinfl-digested genomic DNA ( $3 \mu \mathrm{g}$ ) from TIG-3, and stood for $24 \mathrm{~h}$ at room temperature. The mixture was analyzed by neutral gel electrophoresis using a UD current. A smear band of telomere repeats with a molecular weight higher than that of TIG-3 DNA was observed (Fig. 6B), suggesting co-migration due to complex formation of PCR products with TRF DNA. However, when the same mixture was analyzed by PIF current neutral electrophoresis, smear signal of the mixture showed the same size distribution with that of the TIG-3 
DNA alone at around $6.6 \mathrm{kbp}$, suggesting dissociation of complex in a gel (Fig. 6C). As a control, a plasmid DNA, pAcHLT-A $(8.1 \mathrm{kbp})$ with no telomere repeat sequence, was linearized by EcoRI digestion, ethanol precipitated and mixed with a solution of heat denatured PCR-amplified telomere repeat DNA. When the mixture was analyzed by UD current neutral electrophoresis, smear signal of the plasmid DNA in mixture showed the same size distribution with that of the plasmid DNA alone at around $8 \mathrm{kbp}$, suggesting no complex formation (Fig. 6D left 3 lanes). Right 3 lanes of Fig. 6D showed a Southern blotting using labeled telomere probe, and the size distribution of telomere repeats was the same between telomere repeat DNA alone and mixture of telomere repeat DNA and plasmid DNA. For these experiments, it will be a good idea to isolate and use homogenous fragments of PCR-amplified DNA after cloning a $4 \mathrm{kbp}$ telomere DNA. However, we found that cloned telomere DNA into plasmid very quickly becomes heterogeneous in size during propagation. Therefore, DNA fragment with uniform telomere repeat size could not be obtained even after cloning of bacteria.

G-quartet structure of synthetic telomere repeat DNA is stabilized and shows an increased electrophoretic mobility in nondenaturing gels containing such monovalent cations as $\mathrm{Na}^{+}, \mathrm{K}^{+}$or $\mathrm{Cs}^{+}$, but not in gels containing no added salt. ${ }^{26)}$ Restriction enzyme-digested DNA samples from KMST-6 and TIG-3 were dissolved in 0.5xTBE buffer containing $50 \mathrm{~mm} \mathrm{NaCl}$ and electrophoresed in the same buffer with $\mathrm{NaCl}$ using UD current. As sown in Fig. 7, TRF of KMST-6 did not show a discrete $23 \mathrm{kbp}$ band but showed a wide smear signal with smaller molecular weight. Contrarily, TRF pattern of TIG-3 cells was the same as that observed by electrophoresis in the buffer without additional monovalent cation (compare Fig. 7 with Figs. 3A, 5A, 6B). These data suggested that the association between ECTR DNAs and TRFs observed in DNA samples from ALT cells is likely due, at least in part, to G-quartet formation.

\section{DISCUSSION}

One of characteristics of telomerase-negative immortal (ALT) cells is their extremely long TRFs. ${ }^{9-14)}$ By PF current electrophoresis, telomere length of ALT cells is very heterogeneous from very long to very short. ${ }^{9,25)}$ The other characteristic of telomerase-negative immortal cells is a presence of extrachromosomal telomere repeat (ECTR) DNA. ${ }^{16)}$ In this study, we found that the TRFs of ALT cells are not long by PIF current neutral electrophoresis (Fig. 3). A possible explanation for this discrepancy is, as shown in this study, that a $23 \mathrm{kbp}$ TRF complex was formed between single-stranded tails of the DNA of TRF and ECTR and it was resolved by PIF current electrophoresis. This explanation was supported by our results that a mixture of genomic DNA from TIG-3 and PCR-amplified telomere repeat DNA migrated slower by electrophoresis using UD current than that using PIF current (Fig. 6). From these and other lines of evidence, we concluded that the apparently large TRF in ALT cells is overestimated and represents a complex between TRF DNA and a large number of short ECTR DNA. The real telomere length of ALT cell lines is short as estimated by FISH and PRINS, ${ }^{16)}$ and the long TRF band ( $\left.c a .23 \mathrm{kbp}\right)$ in the conven-

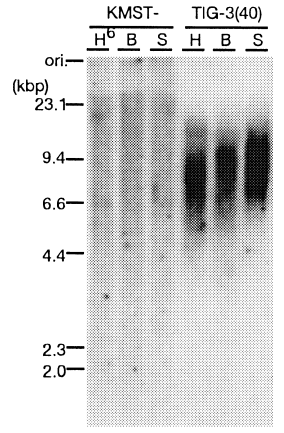

Fig. 7. Electrophoresis of Genomic DNA in Buffer Containing $50 \mathrm{~mm}$ $\mathrm{NaCl}$

Restriction enzyme-digested genomic DNA from KMST-6 and TIG-3 (40 PDL) was dissolved in $0.5 \mathrm{xTBE}$ buffer containing $50 \mathrm{~mm} \mathrm{NaCl}$ and electrophoresed in the same buffer containing $50 \mathrm{~mm} \mathrm{NaCl}$ using UD current. H, Hinfl digested; B, BfaI digested; S, Sau3AI digested.

tional TRF assay by UD or PF current is an artifact. The reason why the complex was formed between ECTR DNA and TRF DNAs from ATL cells but not among TRF DNAs from non-ATL cells is unclear, but is possibly due to high concentration of telomere repeat fragments in DNA from ATL cells.

Although we still could not explain rationally why PIF current electrophoresis gave different results from those by UD or PF current electrophoresis, electrophoresis in different conditions suggests that the presence of ECTR DNA retarded the migration of TRF by making complexes with it under the condition of the conventional UD or PF current electrophoresis. There are several possible mechanisms of complex formation such as mechanical entanglement of double strand DNA, hydrophobic interaction by base stacking, WatsonCrick base-pairing, and G-quartet formation by Hoogsteen base-pairing. Recently, we describe the structural features of a large telomere repeat DNA complex (TRDC) of more than $20 \mathrm{kbp}$, that was generated by a simple PCR using $(\text { TTAGGG })_{4}$ and $(\text { CCCTAA })_{4}$ both as primers and templates. ${ }^{27)}$ Although large as determined by conventional agarose gel electrophoresis, TRDC was found to consist of small telomere repeat single-stranded DNA units between several hundred to $3 \mathrm{kbp}$, indicating that it is a non-covalent complex comprising of short cohesive telomere repeat units. S1 nuclease digestion showed that TRDC contains both single and double strand portions in the molecule. The presumed complex of TRF and ECTR DNAs described in this paper is likely very similar to this TRDC DNA. Complex formation by base-pairing between telomere repeat sequence is also supported by our results that a complex formation (increase in apparent molecular weight) is observed by UD current electrophoresis between PCR-amplified telomere repeat DNA and HinfI-digested TIG-3 genomic DNA but not between PCR-amplified telomere repeat DNA and linearized plasmid DNA which does not contain telomere repeats (Fig. 6). Although we did not extensively examine the nature of the complex, some part of associations between ECTR DNA and TRFs seems to be due to G-quartet formation, because the $23 \mathrm{kbp}$ complex from KMST-6 was resolved showing smear signal with smaller molecular weight in nondenaturing gel (UD current) containing $50 \mathrm{mM} \mathrm{Na}^{+}$(Fig. 7), which is one of characteristics of G-quartet DNA. ${ }^{26}$ )

In this study, ECTR DNA comprising more than $73-83 \%$ of total telomere repeats after alkaline electrophoresis of 
cells embedded in agarose followed by Southern blotting is consistent with a previous observation ${ }^{16)}$ that patches of ECTR DNA were clearly stained by PRINS or FISH but telomeres at the chromosome ends were not detected or only weakly stained in ALT cells such as KMST-6 or SUSM-1. This fact suggests that a majority of TRF DNA does not form a complex with ECTR DNA at telomere ends in situ and that TRF/ECTR DNA complex is formed artificially during purification of genomic DNA. However, if a small portion of telomere repeat fragments is released from a complex of ECTR DNA and interact with telomere repeats at the chromosome ends in the nuclei, the ECTR DNA could function as a source of fragments of telomere repeat DNA for adding to, or for recombining with, terminal telomere repeat DNA, or as a template or primer to elongate telomere DNA at each chromosome end by DNA polymerase resulting in maintaining telomere repeats without telomerase. Telomere terminal DNA forms a loop ( $\mathrm{t}$-loop) where the terminal single-stranded tail invades the double-stranded telomere repeats to form a small loop (D-loop). ${ }^{28)}$ The duplex telomere DNA-binding protein, TRF1, binds along the length of the telomere repeats and TRF2 binds to the D-loop at the junction of the lariat. Detected by in situ staining, ECTR DNA co-localizes with $\mathrm{TRF} 1^{16,17)}$ and with several other protein species, including TRF2. ${ }^{17)}$ Recently, we have isolated ECTR DNA-protein complexes from ALT cell lysate by successive centrifugation and found that the complexes contained several protein bands, revealed by SDS polyacrylamide gel electrophoresis, which included TRF2 confirmed by Western blotting. ${ }^{29)}$

Acknowledgements This work was supported in part by a Grant-in-Aid for Cancer Research and a Grant-in-Aid for Scientific Research on Priority Areas from the Ministry of Education, Culture, Sports, Science and Technology of Japan.

\section{REFERENCES}

1) Moyzis R. K., Buckingham J. M., Cram L. S., Dani M., Deaven L. L., Jones M. D., Meyne J., Ratliff R. L., Wu J. R., Proc. Natl. Acad. Sci. U.S.A., 85, 6622-6626 (1998).

2) Counter C. M., Avilion A. A., LeFeuvre C. E., Stewart N. G., Greider C. W., Harley C. B., Bacchetti S., EMBO J., 11, $1921-1929$ (1992).

3) Harley C. B., Futcher A. B., Greider C. W., Nature (London), 345,
$458-460(1990)$

4) Wellinger R. J., Ethier K., Labrecque P., Zakian V. A., Cell, 85, 423433 (1996).

5) Shay J. W., Pereira-Smith O. M., Wright W. E., Exp. Cell Res., 196, 33-39 (1991).

6) Harley C. B., Mutat. Res., 256, 271-282 (1991)

7) Kim N. W., Piatyszek M. A., Prowse K. R., Harley C. B., West M. D., Ho P. L. C., Coviello G. M., Wright W. E., Weinrich S. L., Shay J. W., Science, 266, 2011-2015 (1994).

8) Shay J. W., Bacchetti S., Eur. J. Cancer, 33, 787-791 (1997).

9) Bryan T. M., Gupta A., Englezou J., Bacchetti S., Reddel R. R., EMBO $J ., 14,4240-4248$ (1995).

10) Murane J. P., Sabatier L., Marder B. A., Morgan W. F., EMBO J., 13, 4953-4962 (1994).

11) Dunham M. A., Neumann A. A., Fasching C. L. Reddel R. R., Nat Genet., 26, 447-450 (2000).

12) Varley H., Pickett H. A., Foxon J. L., Reddel R. R., Royle N. J., Nat. Genet., 30, 301-305 (2002).

13) Bryan T. M., Englezou A., Dalla P. L., Dunham M. A., Reddel R. R., Nat. Med., 3, 1271-1274 (1997).

14) Lundblad V., Blackburn E. H., Cell, 73, 347-360 (1993).

15) Ogino H., Nakabayashi K., Suzuki M., Takahashi E., Fujii M., Suzuki T., Ayusawa D., Biochem. Biophys. Res. Commun., 248, 223-227 (1998).

16) Tokutake Y., Matsumoto T., Watanabe T., Maeda S., Tahara H., Sakamoto S., Niida H., Sugimoto M., Ide T., Furuichi Y., Biochem. Biophys. Res. Commun., 247, 765-772 (1998).

17) Yeager T. R., Newmann A. A., Englezou A., Huschtscha L. I., Noble J. R., Reddel R. R., Cancer Res., 59, 4175-4179 (1999).

18) Namba M., Nishitani K., Fukushima F., Kimoto T., Anticancer Res., 8 , 947-958 (1988).

19) Namba M., Nishitani K., Hyodoh F., Fukushima F., Kimoto T., Int. J. Cancer, 35, 275-280 (1985).

20) Girardi A. J., Weinstein D., Moorhead P. S., Ann. Med. Exp. Biol. Fenn., 44, 242-254 (1966).

21) Fogh J., Trempe G., "Human Tumor Cells in vitro," ed. by Fogh J., Plenum Press, New York, 1975, pp. 115-119.

22) Matsuo M., Kaji K., Utakoj T., Hosoda K., J. Gerontol., 37, 33-37 (1982).

23) Tsuyama N., Miura M., Kitahira M., Ishibashi S., Ide T., Cell Struct. Funct., 16, 55-62 (1991).

24) Kakuo S., Asaoka K., Ide T., Biochem. Biophys. Res. Commun., 263 , 308-314 (1999).

25) Perrem K., Bryan T. M., Englezou A., Hackl T., Moy E. L., Reddel R. R., Oncogene, 18, 3383-3390 (1999)

26) Williamson J. R., Raghuraman M. K., Ceck T. R., Cell, 59, 871-880 (1989).

27) Ohsugi I., Tokutake Y., Suzuki N., Ide T., Sugimoto M., Furuichi Y., Nucleic Acid Res., 28, 3642-3648 (2000).

28) Griffith J. D., Comeau L., Rosenfield S., Stansel R. M., Bianchi A., Moss H., de Lange T., Cell, 97, 503-514 (1999).

29) Tachibana N., Ide T., Tiss. Cult. Res. Commun., 22, 89-100 (2003). 